Original article

\title{
Family-oriented empowerment model influencing quality of life CABG patients
}

\author{
Ali Changizi ${ }^{1}$, Reza Zeighami ${ }^{2}$, Ensie Mirzaei ${ }^{3{ }^{* *}}$, Mahmoud Alipour $^{4}$
}

(Received: 26 July 2014; Accepted 24 Aug 2014)

\begin{abstract}
Background and Purpose: Heart disease death rates have increased worldwide.Family-oriented empowerment model improves the quality of life in the patients with chronic diseases. This study aims to determine the effect of family-oriented empowerment model on the life quality of the patients undergoing coronary artery bypass graft.

Methods: A quasi-experimental study was performed on the patients undergoing CABG in both experimental and control groups before and after the surgery. Samples were put in the groups with a random arrangement and family-oriented empowerment model was applied for the experimental group. Firstly, Mac New Quality of Life Questionnaire was completed for both of them. The four-stage model of threat perception, problem solving, collaboration and training was carried out for the experimental group. One month later, the tools for both groups were completed and the data were analyzed by Mann-Whitney nonparametric test, sign test and SPSS17 software.
\end{abstract}

Results: The mean score of the control group before and after implementing the model was $137.5 \pm 11.6$ and $143.7 \pm 9.6$ $(\mathrm{p}=0.001)$, respectively. They were $133.4 \pm 13.3$ and $148.2 \pm 10.5(\mathrm{p}=0.00)$, respectively in the test group.

Conclusions: These empowering models will lead to improved life quality by developing the inherent capacity of the individuals to take responsibility in life and help to make rational decisions and evaluate them.

KeyWords: Family-oriented empowerment model, Coronary artery bypass surgery, Quality of life, Semi-experimental, Nursing

\section{Introduction}

Today, non-communicable diseases have Cardiovascular diseases resulted in the death of widely prevailed due to the phenomenon termed modernized societies, technological development and population density in urban areas, changes in life style and people's desire to inappropriate habits (1). The prevalence of coronary artery disease largely depends on lifestyle among which smoking, diet and exercise can be mentioned $(2,3)$. Cardiovascular disease is the most important cause of morbidity and mortality in the world (4). 5.16 million people throughout the world in 2002 and it is estimated that the number of deaths due to this disease will reach 25 million in 2020 among which 19 million people will belong to developing countries $(5,6,7)$. Cardiovascular diseases are the most common causes of death in our country, too (8). Coronary Artery Disease (CAD) is the first cause of death in Iran and accounts for $46 \%$ of all cause of deaths in the country (9).

\footnotetext{
${ }^{1}$ Department of Cardiology, Medical Sciences School, Qazvin University of Medical Sciences, Qazvin ,Iran, Iran ${ }^{2}$ Department of Critical Care Nursing, Nursing and Midwifery School, Qazvin University of Medical Science, Qazvin 3,* Corresponding author: Department of Critical Care Nursing, Nursing and Midwifery School, Qazvin University of Medical Science, Qazvin, Iran. Email: HYPERLINK "mailto:e_mir1934@yahoo.com"e_mir1934@yahoo.com

${ }^{4}$ Department of Biostatistics, Qazvin University of Medical Sciences, Qazvin, Iran
} 
CAD is a chronic one which not only has a high number of deaths, but in the long run also creates restriction on a person's life (10). It is estimated that cardiovascular diseases were the first incapacitating reasons in the list of the debilitating diseases in the world until 2020 (11).

CABG is essential in treating coronary artery diseases and currently it has been one of the most common surgical procedures (12). The American Society of Thoracic Surgeons announced that in 85 percent of the patients undergoing heart surgery, CABG has been performed (13). In Iran, 60 percent of the cardiac surgery is associated with coronary artery bypass surgery (14).

The prevalence of coronary artery bypass graft surgery rises among young people with coronary artery disease the most common reason behind which is using inappropriate diets (15).

Changes in the pattern of the diseases led to the reduction of infectious diseases and increasing longevity and increased attention to the concepts of health and quality of life during the past decade. The importance of life quality and health status is to the extent that health care experts have expressed focusing on improving life quality and health status in the present century (16). Life quality indicates personal perception of life in different aspects such as physical and psychosocial functions which is in line with the patients' standards and expectations (17). Chronic diseases such as diabetes and cardiovascular diseases are the most common causes of social, physical and mental problems that result in functional limitation and reduced quality of life. In MI patients, since the patients are facing decreased heart and physical capacity preceded by ischemic heart attacks life quality is affected by this change (18). Boosting the quality of life by lowering the disease effects is the primary goal of treatment especially in chronic diseases (19).

The importance of life quality is so much that its improvement is considered as the most important intervention treatment objective. This matter becomes significant for chronic diseases for which no definitive treatment exists (20). One of the most common chronic diseases in the recent years is cardiovascular diseases (21). Patients who have undergone coronary artery bypass graft surgery are the ones that may create some changes in the family system and as a result, some problems for their families. They may have unique needs and health services may not have been predicted for them, especially to support their families and other caregivers (22).

Considering that heart disease can last for a lifetime, and in addition to the patient, the family and even the community are also affected in this procedure; it is necessary for the patient to be empowered in order to be able to control the disease better and promote life quality. The concept of empowerment has been used in chronic patients' care since 2004 (23) and in diabetes, it has been defined as the process of discovering and developing personal capacity to take the responsibility of the life by having the knowledge and resources to obtain and implement the logical choice and enough experience to evaluate the effectiveness of decisions for the first time (24). Many experts believe that empowerment is a dynamic, positive $(25,26)$, social and interactive process $(27,28)$. It is a process formed by communicating with others (27) leading to the improvement of life quality, accountability, better interaction with health authorities, satisfaction(28), better response to treatment $(29,30)$, the prevention of complications(31), the reduction of healthcare costs (32) and a positive view about the disease (33).

One of the key steps to achieve this goal is to use nursing models according to the theories and models of clinical care, education and research activities (34). Family-oriented empowerment model has been designed emphasizing the effectiveness of the individual and other family members' role in the areas termed as motivation, psychologyical status, knowledge, attitudes and the perceived threat. This model has been emerged from the qualitative research of "fundamental theory". It has created a functional model by forming concepts, developing concepts, identifying the psychological and social processes 
and deducting empowering family-oriented central variable (34). This model has been implemented to improve the life quality pof the patients stricken with chronic iron deficiency anemia (34), Thalassemia (35), diabetes (36), asthma (37) and multiple sclerosis (38).

Helping families is the purpose of empowerment in such a manner that can be changed (39). Familyoriented care is a health care approach that can form health care philosophy, plans, strategies, and design simplicity, patients, families and physicians and other health professionals' daily interactions (40). In familyoriented education, there is an active participation of the families in the study and the diagnosis of training and the needs. Since empowerment and self-care advice are directly linked, that is, when nurses help heart patients to identify their problems and learn new skills that are important for them; they enable patients to solve their problems. Most studies have been related to coronary artery bypass surgery and less attention has been paid to satisfaction and life quality of these patients and their families (41).

Based on the objective of family-oriented empowerment model effect on quality of life, the results of the research by Soleymani et al. (2010) showed that applying this model on a regular basis can increase the quality of life (42).

Masoudi (2010) implemented empowerment model in the context by assessing the impact of this model on knowledge, attitude and the practice of caregivers to the patients suffering from multiple sclerosis. He concluded that empowering caregivers to MS patients lead to increase their knowledge, understanding and skills and effectively assist them in the care issue and enhance their roles. Due to this model's impact on knowledge, attitude and performance, we expect that this model can increase the ability of the patients' family members undergoing coronary artery bypass graft and indirectly improve their quality of care and also their quality of life (43). Patients can reach a sense of personal empowerment through education and facilitate their access to the necessary resources. It should be noted that the effect of this model has not been studied in these patients so far.

This study aims to evaluate the effect of familyoriented empowerment model on the quality of life in patients undergoing coronary artery bypass graft.

\section{Materials and Methods}

This is a quasi-experimental study. The study was performed on both the experimental and control groups before and after the surgery. The study population included all patients who had coronary artery bypass graft surgery. The sample consisted of the patients with coronary artery bypasses from the beginning to the end of the sampling procedure in Qazvin Avicenna Hospital. Fifty samples in each group were tested. Sampling method was available sampling. All the eligible patients were enrolled. Integration was performed using the same inclusion criteria.

Inclusion criteria covered the patients having coronary artery bypass graft surgery and with no hearing or vision problems and lacking mental or neurological problems and education or higher degree license and not living in elderly nursing home. And exclusion criteria encompassed the patient not cooperating or participating in the meetings, hospitalizations, serious complications that were associated with the surgery. According to the objective and confidence coefficient of $95 \%(\alpha=0.05)$ and capability of $80 \%$, and regarding the variance and the mean before and after the inclusion in the previous studies, the minimum sample requirement was $\mathrm{n}=50$ by taking the loss into account in each group

8 subjects were excluded and totally 93 patients in each group were studied. Samples were divided into the control and experimental group randomly. And the implementation of family-oriented empowerment model Intervention was included in the experimental group.

The study was conducted in three phases and informed consent was obtained from the samples before starting it. The tools consisted of two parts in this study. First, the demographic information questionnaires such as age, sex, education level, occupation, marital status and family member's education, gender and age collected by 
the researcher. Second, Mac New QOL questionnaire that was specifically designed to measure the cardiac patients' quality of life. This questionnaire evaluated the cardiac patients' quality of life with three subscales of emotional, physical, and social functioning. Fourteen questions are related to physical function and fourteen questions to emotional function and also thirteen questions to social function areas. Five questions of physical functions evaluate patient symptoms. Classifying the questionnaire questions was so that each question can be found in one, two or all three areas. Thus, the mean physical function score is calculated by the mean scores of 14 questions in this field and so as the other functions. The final score is estimated by calculating the scores of all questions. Each questionnaire's question contains seven degrees of response criterion. Each response has position on a continuum ranging from Always to Never. The highest possible score in each area is the score of 7 and the lowest score is one indicating high and low life quality, respectively.

The validity and reliability of this instrument has been approved by Hofer on the patients with myocardial infarction. It has had acceptable reliability by the correlation coefficient and interdependence of 0.73(44). Bagheri has changed the questions according to the patients' status and their conditions in Iran. Scientific validity of this questionnaire resulted from content validity and was used on the patients with myocardial infarction with reliability coefficient 0.92 (45). Besides, this tool was localized by Asadi-Lari study in the patients with myocardial infarction in 2003. The internal correlation in THE emotional and physical areas was reported by alphaCranach coefficient 0.92 and the coefficient 0.94 for social area and 0.95 for all the areas (46). Also this tool has been applied in the patients with myocardial infarction, heart failure and pacemaker. To determine the face and content validity, this questionnaire has been handed to some professors and the comments have been implied, then twenty patients answered the questionnaire. In order to determine the reliability of the data $\alpha$-Cronbach coefficient has been used as 0.935 and its reliability has been confirmed.

In the first step that is the pre-intervention one, the research instruments were completed by the samples in both groups. The second step (intervention) was implemented just for the experimental group. The intervention, that is, family-oriented empowerment model was performed based on the mentioned steps and 1-2 days after the surgery and stabilizing the patient's status. Each step was conducted in 1-2 sessions each within 30-45 minutes (34).

In the first step, that is, the threat understanding, the patients' problems were introduced with at least one family member as a group discussion by increasing the knowledge and awareness about the disease and its complications and treatment. Then for the second run, the participants' problems (patients and family members) were extracted during the previous sessions. At this step ( problem solving), plus deep knowledge of the disease process and its complications, the patients had active participation in their care plan with selfconfidence and educational pamphlets and booklets in the field of activity, surgical site care, subsequent visits with the doctor, nutrition, the prevention of infection, asleep and warning symptoms were presented to the participants. And their questions were answered.

Moreover, the practical approach was used to learn new skills. Thus the practical skills required for each patient has been first described and then those skills have been displayed for them.

The mobility program after surgery and the problems resulting from failure to perform them have been explained theoretically for the patients. Then the practical application steps like stretching exercises have been done completely in front of the patients to learn. Skills have been later divided into smaller parts and done step by step and the patient has been asked to do each task. Then the patient has been allowed to be practice to get skilled in that behavior.

The patient has been asked to repeat the exercise to be able to do it alone. And finally the patient has got efficient in that skill. In order for the family participation in patient care, these training and pamphlets have been 
provided for family members by the participants in the third step (the educational participation).

In this step, the family has been considered as a source of support to improve the process of empowerment through self-improvement and self-esteem.

The model fourth step (evaluation) consists of two parts: First, it has been the evaluation process for each session done by asking a few questions about the matters presented in the previous sessions to ensure the mental and practical contribution to the care plan and the required follow-up. Then, the final evaluation questionnaires have been completed by the patient's life quality questionnaire one month after the intervention in the intervention group and one month after completing life quality questionnaire in the control group.

These evaluations have been done in order to determine the effectiveness of completing life quality questionnaire.

To start, the license has been received from the Vice Chancellor for Research and Avicenna colleagues. The project objectives were explained to all participants and informed and written consent and voluntary participation in the project was received. It was explained for the participants that they were allowed to leave the plan at any time and their name will remain confidential. Educational materials such as the pamphlets and the educational software related to the intervention group were provided for the control group. The control group got the surgery issues about all of the patients. This educational program consisted of educational pamphlets on the care, the use of medications, alarm signs and times of visit given to the patient and the family member as well as face to face training has been run for the patient and the family members. This education is without qualification.

After filling in the questionnaires, Mann-Whitney test has been taken to compare the life quality scores between the two groups, T-test to compare the three sub-scales of physical, mental and social groups, paired t-test to compare pre-tests \& post-tests for each group and ANOVA for the comparison of life quality and demographic variables in SPSS17 was used to analyze the data.

\section{Results}

The standard deviation and the mean age of the participants were $(59.6 \pm 5.917)$.

Among the experimental group, $72.7 \%$ (32 persons) were men and $27.3 \%$ (12 persons) were women. And in the control group, 66.7 percent $(n=32)$ were men and $33.3 \%(n=16)$ were women. Totally, 69.6\% (64 persons) men and $30.4 \%$ (=28 persons) women were studied in this research. 90 persons $(97.8 \%)$ of the study cases were under diploma educational level. In total, 90 persons $(97.8 \%)$ had diploma and 2 persons (2.2\%) had no diploma.

Depending on the significant diseases, 32 persons $(66.3 \%)$ out of the subjects had only one type of significant disease (with background).

In the experimental group, 6 patients $(6.13 \%)$, with a diagnosis of myocardial infarction and 38 patients $(4.86 \%)$ with a diagnosis of unstable angina were admitted to the hospital.

In the control group, unstable angina was superior and 46 patients $(95 \%)$ with a diagnosis of unstable angina and 2 patients $(2.4 \%)$ with a diagnosis of stroke were included in the study. Generally, Kolmogorov-Smirnov statistic life quality 48.1 and a significance level 0.025 represents that the scale is not normal. So to compare the two groups, the Mann-Whitney non-parametric test was used. In the sub-scales, Kolmogorov-Smirnov statistic significance level was $>0.05$; therefore the subscales had normal distribution and the independent t-test was used to compare the two groups.

The independent $\mathrm{t}$-tests within the mental, emotional and social areas, before and after the intervention, have showed significant statistical differences in the scores of life quality compared with the control group. Since P-value $=0.05$, so there was no significant difference between the test and control groups on the physical aspect.

Since $\mathrm{P}$-value $=0.008$, there was a significant difference between the two groups on the social aspect. And finally, P-value is 0.03 on the emotional 
aspect so there was a significant difference between the two groups.

The significance level of leven test equals 0.003 and is smaller than 0.05 , so the assumption of equal variances is rejected. P-value in t-test equals 0.38 and $>0.05$; there is no significant difference in the quality of life between men and women.

There is no meaningful relationship between quality of life and age. Significance level between the quality of life and disease duration equals 0.036 and is smaller than 0.05 , so there is a meaningful relationship between quality of life and disease duration. This relationship is weakly positive. There is no significant difference between the types of disease and quality of life.

Table 1. Comparison of quality of life subscales between the experimental and control groups

\begin{tabular}{lccccc}
\hline \multicolumn{1}{c}{ Scales } & Group & NO. & $\begin{array}{c}\text { Pre-test } \\
\text { Mean } \\
\text { \&S.D }\end{array}$ & $\begin{array}{c}\text { Post-test } \\
\text { mean\& } \\
\text { S.D }\end{array}$ & P-value \\
\hline $\begin{array}{l}\text { Physical } \\
\text { aspect }\end{array}$ & Experimental & 44 & $37.72 \pm 4.66$ & $41.50 \pm 2.92$ & 0.056 \\
$\begin{array}{l}\text { Social } \\
\text { aspect }\end{array}$ & Control & 48 & $38.18 \pm 3.87$ & $40.06 \pm 2.83$ & 0.059 \\
$\begin{array}{l}\text { Emotional- } \\
\text { mental } \\
\text { aspect }\end{array}$ & Experimental & 44 & $65.79 \pm 7.72$ & $73.81 \pm 5.84$ & 0.030 \\
\hline & Control & 48 & $68.06 \pm 7.47$ & $72.16 \pm 5.94$ & 0.030 \\
\hline
\end{tabular}

Table 2. Comparison of pre-test \& post-test mean score in the experimental group

\begin{tabular}{lcccc}
\hline $\begin{array}{c}\text { Experimental } \\
\text { group }\end{array}$ & Step & No. & Mean \& S.D & $\begin{array}{c}\text { P-value } \\
\text { (independent t-test) }\end{array}$ \\
\hline Total scale & Pre-test & 44 & $133.45 \pm 13.37$ & $<0.001$ \\
& Post-test & 44 & $148.25 \pm 10.59$ & \\
& Pre-test & 44 & $37.72 \pm 4.66$ & $<0.001$ \\
Physical aspect & Post-test & 44 & $41.50 \pm 2.92$ & \\
Social aspect & Pre-test & 44 & $29.93 \pm 3.55$ & $<0.001$ \\
& Post-test & 44 & $32.9 \pm 3.50$ & \\
$\begin{array}{l}\text { Emotional- } \\
\text { mental aspect }\end{array}$ & Pre-test & 44 & $65.79 \pm 7.72$ & $<0.001$ \\
\hline
\end{tabular}

\section{Discussion}

Along with the quality of life, health is defined as an individual's conception in relation to improvement and mental and physical performance capacity. This concept affects every aspect of life (47). This research has demonstrated that family-oriented empowerment model improves the quality of life in the patients undergoing coronary artery bypass graft surgery. Different aspects of quality of life, especially social and emotional-mental aspects have been improved in these patients by applying this model. So, these patients can improve their self-care and interdependence. One month after the intervention, quality of life scores showed that a significant increase in all three aspects of physical, mental and social have been observed in the experimental group.

Although, quality of life scores increased in the control group compared to that of before the surgery, this increase was higher in the experimental group and QOL scores increased in all three aspects compared with that before the surgery. This rate is not meaningful in the control group. Physical criteria evaluation related to the quality of life in the patients with coronary disease is very important and shows that this criteria score has increased in experimental group after one month intervention. This also implies the effect of family-oriented empowerment model employed in this group of the patients.

The implementation of family-oriented care creates positive feelings in health care workers. By these actions, family understanding and participation in caring these patients promote at home and their anxiety gets lower (48). This research suggests the rehabilitation programs of family-oriented empowerment model. The research results by Smith et al. (2002) denoted that after implementing these programs, a meaningful difference has been seen between the two groups in the physical and social functioning, general health and physical limitations (49). The research by Fayyazi et al. (2011) suggested that the quality of life has not improved in the patient's mental aspect without running any care program and the model one and three months after CABG surgery. The study by Kargar najafi et al. in Kerman revealed that family-oriented empowerment model improved life quality in the patients with 
thalassemia the results of which match with those of our research (50).

The clinical trials results by Vahedian Azimi (2009) and Teymouri (2011) show that family-oriented empowerment model boosted the quality of life in the patients with myocardial infarction and asthma through group discussion, demonstration and practical work in partnership $(43,37)$.

Aggarwal et al. (2010) asserted that social support for cardiovascular patients is one of the most important factors complying the treatment after hospital discharge .In the patients who did not have family complying with the treatment, it significantly decreased $(p<0.05)$, according to the survey results that after heart surgery the patient's physical dimension got improved, this study can be considered consistent with the current research (53).

Regarding the present study results indicating a significant difference in the psychological and mental aspects scores of family-oriented empowerment model, this model can be used as a substitute for counseling programs in the patients undergoing coronary artery bypass graft surgery. Since in this model, all the factors affecting the problems associated with surgery have been considered (physical activity, diet, medicines, how to do the activities, post-operative care, stress management, wound care, blood pressure monitoring and warning signs and so on) and family involvement in the follow-up measures and training them perceived as a principle, post-intervention life quality has got enhanced compared with that of the pre-intervention.

Because one of the basic problems in the patients having chronic disease is their life quality and how to spend their lifetime, this study had a remarkable impact on the quality of life in these patients as the most basic control parameters.

As there is no specific location for the patients and families to be educated, the training was carried out at the patient's bedside. This reduced the concentration of the trainers and trainees. It is recommended that this point be considered preferably in implementing the family-oriented empowerment model. Also, ICU postal sector for the patients hospitalized there before and after the surgery, the education follow-up and family-oriented empowerment model implementation created many problems for the researchers. Albeit, with specialized and sub- specialized clinics, frequent and regular reference one month after the surgery and completing tools follow-up after intervention and third step implementation, this research was simplified and there was no need to refer to the patient's home or to the hospital.

\section{Conclusion}

With a brief overview of the data analysis and findings, it will be determined that family-oriented empowerment model creates a significant difference in various levels of life quality in the patients after coronary artery bypass graft surgery. So this model enhances life quality in these patients. Quality of life scores increasing in the experimental group indicates family empowerment. Although the scores increasing of the control group was not so much. Because the groups matched greatly in terms of the influential factors, life quality improvement can be attributed to the influence of this model.

According to the obtained results, it is suggested that family-oriented empowerment model be replaced by common education for these patients. It must be implemented for the patients with acute coronary syndrome as well as the other patients suffering from heart disease and their results must be evaluated.

\section{Conflict of interests}

The authors declare that they had no competing interests.

\section{Author's contributions}

A.Changizi and R.Zeighami have contributed to designing, revising and approving the final manuscript. Statistical analysis has been performed by M.Alipour. Data collection and writing have been done by E.Mirzaei. 


\section{Acknowledgments}

This article is drawn from a master's thesis titled "Effect of family-oriented empowerment model on the quality of life in the patients undergoing coronary artery bypass graft surgery in the Avicenna hospital". It has been approved in the School of Nursing and Midwifery in Qazvin University of Medical Sciences in 2013. The authors of this article appreciate all the patients for their sincere cooperation and all the colleagues and leaders of Avicenna hospital and its specialized and sub-specialized clinics.

\section{References}

1. Mashhad University of Medical Sciences Portal, Health \& Food Security Council [homepage on internet]. Prevention of cardiovascular diseases; 2008. Available from: https: www.mums.ac.ir.CHFS.fa.index.

2. Teramoto T, Sasaki J, Ueshima H, Ishibashi S, Birou S, Daida $\mathrm{H}$ et al. Risk factors of atherosclerotic diseases. Executive summary of Japan Atherosclerosis Society (JAS) guideline for diagnosis and prevention of atherosclerosis cardiovascular diseases for Japanese. J Atheroscler Thromb. 2007; 14(6): 267-277.

3. Yagi H, Komukai K, Hashimoto K, Kawai M, Ogawa T, Anzawa R, et al. Difference in risk factors between acute coronary syndrome and stable angina pectoris in the Japanese: smoking as a crucial risk factor of acute coronary syndrome. J Cardiol. 2010; 55(3): 345-353.

4. Jamshidi N, Abbaszadeh A, NajafiKalyani M. The Effects of video education on comfort and tolerability of patients undergoing coronary angiography. Iranian Journal of Nursing Research. 2010; 5(16): 38-44 (Persian).

5. Lukkarian $\mathrm{H}$, Hentinen M. Treatments of coronary artery disease improve quality of life in the long term. Nurs Res. 2006: 55(1): 26-33.

6. Maclin DR, Chokalingam A. The global burden of cardiovascular disease, Canadian Cardiovascular Soci Bulletin. 2002; 1: 1-3.

7. Murray CJl, Lopez AD, Eds. The global burden of mortality and disability from disease, and risk factors in 1990 and projected to 2020. 1st ed. Cambridge:
Harvard University Press; 1996.

8. Vahedian Azimi A, Alhani F, Ahmadi F, Kazemnejad A. Effect of family-oriented empowerment model on the life style of myocardial infarction patients. Iranian Journal of Critical Care Nursing. 2010; 2(4): 127-132.

9. Tofighi Sh, Ahmad Kiadaliri A, Sadeghifar J, Raadabadi M, Mamikhani J. Health-related quality of life among patients with coronary artery disease: A posttreatment follow-up study in Iran. Hindawi Publishing Corporation Cardiology Research and Practice. 2012; 1: $1-6$.

10. Zipes DP, Braunwald E. Braunwald'S heart disease: A textbook of cardiovascular medicines.7th Ed. Philadelphia; WB Saunders; 2005.

11. Kuller LH. Epidemiology of cardiovascular diseases: current perspectives. Am J Epidemiology. 1976; 104(4): 425-496.

12. FinkelmeierBA. Cardiothoracic surgical nursing 2th ed. Philadelphia,W.B.Lippincott; 2000.

13. Kirklin JW, Barratt BoyesGB. Cardiac surgery. morphology, diagnostic criteria, natural history, techniques, results, and indications. 2th ed. New York, Churchill Livingstone; 1993.

14. Babaee G, Keshavarz M, Heidar nia A, Shayegan M. Effect of a health education program on quality of line in patients undergoing coronary artery bypass surgery. Acta media Iranica 2007; 45(1): 69-74.

15. Atkov OY, Gorokhova SG, Sboev AG,Generozov EV, Muraseyeva EV, Moroshkina SY, et al. Coronary heart disease diagnosis by artificial neural networks including genetic polymorphisms and clinical parameters. J Cardiol. 2012; 59(2): 190-194.

16. Gioiella EC. Quality of life revisited. Nurs Sci Quart. 1995; 8(3): 97. PMID: 7651632.

17. Saeidi M, Mostafavi S, Heydari H, Masoudi S. Effects of a comprehensive cardiac rehabilitation program on quality of life in patients with coronary artery disease. Arya Atheroscler. 2013; 9(3): 179-185.

18. Zendehtalab H, Vaghei S, Emami Moghaddam Z.: Effect of intervention based on BASNEF model on quality of life in patients with type 2 diabetes. Journal Evidence Based Care. 2013; 3(1): 7-16 (Persian).

19. Rooh afza H, Sadeghi M, Boshtam M, Rbiei K, 
Khosravi E. Effects of a cardiac rehabilitation course on psychological stresses in an Iranian population. ARYA Atheroscler. 2012; 7(Suppl): 74-77.

20. Ahmadi F, Salar A, Faghih-zadeh S. Review the quality of life in Zahedan elderly. Hayat, J of Tehran Univ Med Sci. 2004; 10(22): 61-67.

21. Loghmani L, Jaryabi A, Borhani F. Influence of preoperative education depression in patients after open heart surgery. Daneshvar Med. 2006; 14(67): 33-42.

22. Rantanen A, Kaunonen M, Astedt KP, Tarkka MT. Coronary artery bypass graft: social support for patients and significant others, J Clin Nurs. 2004; 13(2): 156166. PMID: 14723667.

23. Funnell MM, Anderson RM. Empowerment and selfmanagement of diabetes. Clin Diabetes. 2004; 22(3): 123-127.

24. Mok E, Martinson I, Wong TK. Individual empowerment among Chinese cancer patients in Hong Kong. West $\mathrm{J}$ Nurs Res. 2004; 26(1): 59-75. PMID: 14984648.

25. Wahlin I, Ek AC, Idvall E. Patient empowerment in intensive care- an interview study. Intensive Crit Care Nurs. 2006; 22(6): 370-377. PMID: 16890438.

26. Gibson $\mathrm{CH}$. The process of empowerment in mothers of chronically ill children. J Adv Nurs. 1995; 21(6): 1201-1210. PMID: 7665789.

27. Arvidsson SB, Petersson A, Nilsson I, Andersson B, Arvidsson BI, Petersson IF, et al. A nurse-led rheumatology clinic's impact on empowering patients with rheumatoid arthritis: A qualitative study. Nurs Health Sci. 2006; 8(3): 133-139. PMID:16911172.

28. Roberts KJ. Patient empowerment in the united state: A critical commentary. Health Expect. 1999; 2(2): 82-92. PMID: 1281882.

29. Ghavasse BG, Strauss AL. New dimensions of empowerment in nursing -and challenges. J Adv Nurs. 1992; 17(1): 1-2.

30. Nute R. Standard 3-empowering people with diabetes. Prim Health Care. 2004; 14(3): 35-37.

31. Shiu AT, Wong RY, Thompson DR. Development of a reliable and valid Chinese version of the diabetes empowerment scale. Diabetes Care. 2003; 26(10): 2817-2821. PMID: 14514585.

32. Koch T, Jenkin P, Kralik D. Chronic illness self- management: Locating the' self. J Adv Nurs. 2004; 48(5): 484-492. PMID: 15533086.

33. Anderson RM, Funnell MM. Patient empowerment: reflections on the challenge of fostering the adopting of a new paradigm. Patient Educ Couns. 2005; 57(2): 153-157. PMID: 15911187.

34. Alhany F. Design and evaluation of family- centered empowerment model for prevention of iron, thesis. Tarbiate Modarres University; 2004 (Persian).

35. Alhani F, Alahyari A, Kazemnejad A. The effect of family-centered empowerment model on the quality of life of school-age B-thalassemiac children. Iranian Journal of Pediatrics. 2006; 16(4): 455-461.

36. Razi SH, Sadeghi M, Nikbakht Nasrabadi A, Ebrahimi H, Kazemnejad A. Effect of family-centered empowerment model on knowledge and metabolic control of patients with type 2 diabetes knowledge \& health Journal. 2014; 9(1): 48-54.

37. Teymouri F, Alhani F, Kazemnejad A. Effect of familycentered empowerment model on the quality of life of school-age asthma children. Journal of Nursing Research. 2011; 6(20): 52-63.

38. Masoodi R, Alhani F, Moghaddasi J, Ghorbani M. The effect of family-centered empowerment model on skill,attitude, and knowledge of multiple sclerosis caregivers. Journal of Birjand University of Medical Sciences. 2010; 17(2): 87-97.

39. Adams EK, Gavin NI, Ayadi MF, Santelli J, RaskindHood C. The costs of public services for teenage mothers post-welfare reform: a ten-state study. J Health Care Finance. 2009; 35(3): 44-58. PMID: 19891207.

40. Campbell LC, Keefe FJ, McKee DC, Edwards CL, Herman SH, Johnson LE, et al. Prostate cancer in African Americans: relationship of patient and partner self-efficacy to quality of life. J Pain Symptom Manage. 2004; 28(5): 433-444. PMID: 15504620.

41. Lenz E, Perkins SH. Coronary artery bypass graft surgery patients and their family member caregivers; outcomes of a family - focused staged psychoeducational Intervention. Appl Nurs Res . 2000; 13(3): 142-150. PMID: 10960998.

42. Masoodi R, Alhani F, Moghaddasi J, Ghorbani M. Effect of family-centered empowerment model on 
skill, attitude, and knowledge of multiple sclerosis caregivers. Journal of Birjand University of Medical Sciences. 2010; 17(2): 87-97 (Persian).

43. Vahedian Azimi A, Alhani F, Ahmadi F,Kazemnejad A. Effect of family-centered empowerment model on the life style of myocardial infarction patients. Iranin Journal of Critical Care Nursing. 2010; 2(1): 1-2 (Persian).

44. Hofer S, Lim L, Guyatt G, Oldridge N. The Mac New heart disease health-related quality of life instrument. Health Qual Life Outcom. 2004; 2(1): 3-10.

45. Bagheri H. Effects of group counseling program on quality of life of patients with myocardial infarction referrd to clinics affiliated to Tehran Medical Universityies Hospitals (Master Thesis). Tehran: Tarbiat Modarres University; 2001(Persian).

46. Asadi-Lari M, Javadi H, Melville M, Martin R, Oldridge N, Gray D. Adaptation of the MacNew quality of life questionnaire after myocardial infarction in an Iranian population. Health Qual Life Outcome. 2003; 1(1): 23-28.
47. Rantanen A, Kaunonen M, Tarkka M, Sintonen H, Koivisto AM, Astedt-Kurki P, et al. Patients' and significant others' health-related quality of life one month after coronary artery bypass grafting predicts later health-related quality of life. Heart Lung. 2009; 38(4): 318-329. PMID: 19577703.

48. Perry AG, Potter PA. Fondamentals of nursing. 5 Th ed. Missouri ,Mosby Co; 2001.

49. Lindsay GM,Hanlon WP,Smith LN, Belcher Pr. Experience of cardiac rehabilitation after coronary artery surgery: effects on health and risk factors. Int $\mathrm{J}$ Cardiol. 2003; 87(1): 67-73. PMID: 12468056.

50. Lefebvre H, Levert MJ, Pelchat D, Lepage JG. Nature, sources, and impact of information on the adjustment of family caregivers: a pilot project. Can J Nurs Res. 2008; 40(1): 143-160. PMID: 18459277.

51. Aggarwal B, Liao M, Allegrate P, Mosca L. Low social support level is associated with non- adherence to diet at 1 year in the family intervention trial for heart health (FIT Heart). J Nutr Educ Behav. 2010; 42(6): 380-388. PMID: 20696617. 